\title{
Commentary: Intraoperative electromagnetic percutaneous localization by surgeons: Navigating the rough waters of indeterminate pulmonary nodules
}

\author{
Abbas E. Abbas, MD, MS, FACS
}

\footnotetext{
From the Division of Thoracic Surgery, Department of Thoracic Medicine and Surgery, Lewis Katz School of Medicine at Temple University, Philadelphia, Pa.

Disclosures: Author is a paid consultant for Boston Scientific, Inc and Intuitive Surgical, Inc. Neither entity was involved in the preparation of this article.

Received for publication Dec 17, 2018; accepted for publication Dec 18, 2018; available ahead of print Jan 31, 2019.

Address for reprints: Abbas E. Abbas, MD, MS, FACS, Department of Thoracic Medicine and Surgery, Temple University Health System, Lewis Katz School of Medicine, 3401 N Broad St, Suite C-100, Philadelphia, PA 19035 (E-mail: abbas.abbas@temple.edu).

J Thorac Cardiovasc Surg 2019;157:e215-6

$0022-5223 / \$ 36.00$

Copyright (C) 2018 Published by Elsevier Inc. on behalf of The American Association for Thoracic Surgery https://doi.org/10.1016/j.jtcvs.2018.12.062
}

Screening for cancer and other lung disease by computed tomographic (CT) scan has led to a dramatic rise in diagnosis of indeterminate pulmonary nodules (IPNs). ${ }^{1}$ These may be so small, faint, or deep that neither bronchoscopy nor CT-guided needle biopsy is possible. It often falls on the surgeon to attempt resection of these indeterminate nodules. Of course, the very characteristics that make them difficult to sample for biopsy are the same ones that make IPNs challenging to find at the time of resection.

It is therefore often helpful to use localization techniques, which vary according to the imaging modality (eg, CT or ultrasound) or the marker used (eg, fiducial, wire, or liquid dye). As far as the surgeon and the patient are concerned, however, it is perhaps more important whether localization is done at the time of surgery or before, and whether it is done by the actual surgeon who will be searching for the nodule or by a different specialist. Unfortunately, most of these procedures are typically done preoperatively, by a nonsurgeon.

Our group and others in the surgical community have previously discussed the many benefits of intraoperative localization by the surgeon, including the avoidance of delay in treating a biopsy-related complication, patient convenience, and the ability of the surgeon to place the marker according to the planned angle of approach to the IPN. ${ }^{2-4}$ Despite these benefits, few intraoperative studies have been published. A recent report by our group ${ }^{5}$ described electromagnetic navigational bronchoscopic injection of autofluorescent dye for localization of small, deep, or subsolid IPNs. This technique was successfully used to localize 53 of 54 IPNs $(98.15 \%)$, allowing simultaneous robotic sublobar resection.

In their article in this issue of the Journal, Hsu and $\mathrm{Wu}^{6}$ describe their use of the SPiN Perc thoracic navigation system (Veran Medical Technologies, St Louis, Mo) for

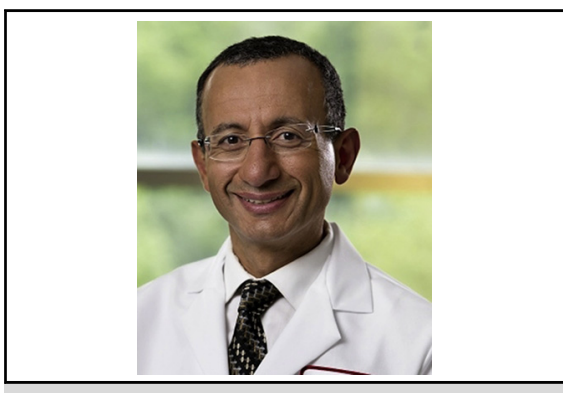

Abbas E. Abbas, MD, MS, FACS

Central Message

Electromagnetic navigation for percutaneous localization of nodules is an ideal tool that closely mimics the planned resection approach. It can be performed intraoperatively by the same surgeon.

See Article page e211.

percutaneous insertion of a microcoil and injection of a liquid marker at the pleural surface. Fluoroscopy was used to guide the thoracoscopic resection of 6 IPNs. The mean distance between the nodule and microcoil was $4.2 \pm 5.0 \mathrm{~mm}$, and no complications were associated with the procedure.

The system uses an electromagnetic field for percutaneous or endobronchial navigation. Sensors permit real-time tracking of the needle and respiratory gating. Unmentioned but unique benefits of this technique include localizing the IPN with the patient in the same lateral decubitus position as used for the operation. In addition, the percutaneous approach more closely simulates the planned line of attack by the surgeon than does bronchoscopic localization. Also, unlike localization done by a nonsurgeon, which is usually according to the shortest path to the nodule, this technique allows localization of the overlying pleural surface that will be included in the predicted wedge resection.

It is undoubtedly a frustrating experience when a surgeon searches for but is unable to find a lung nodule. What should be a simple, minimally invasive procedure can turn into a major operation-or worse, a missed malignancy. This small study should serve as an impetus for larger scale evaluation of a unique approach that may allow thoracic surgeons to successfully and electromagnetically navigate the rough waters around a difficult nodule. 


\section{References}

1. Krochmal R, Arias S, Yarmus L, Feller-Kopman D, Lee H. Diagnosis and management of pulmonary nodules. Expert Rev Respir Med. 2014;8:677-91.

2. Shulman RM, Abbas AE. The state of the art and future directions of robotic-assisted thoracic surgery. Ind J Thorac Cardiovasc Surg. 2018;34(1 Suppl):40-6.

3. Anayama T, Qiu J, Chan H, Nakajima T, Weersink R, Daly M, et al. Localization of pulmonary nodules using navigation bronchoscope and a near-infrared fluorescence thoracoscope. Ann Thorac Surg. 2015;99:224-30.
4. Kondo R, Yoshida K, Hamanaka K, Hashizume M, Ushiyama T, Hyogotani A, et al. Intraoperative ultrasonographic localization of pulmonary ground-glass opacities. J Thorac Cardiovasc Surg. 2009;138:837-42.

5. Abbas A, Kadakia S, Ambur V, Muro K, Kaiser L. Intraoperative electromagnetic navigational bronchoscopic localization of small, deep, or subsolid pulmonary nodules. J Thorac Cardiovasc Surg. 2017;153:1581-90.

6. Hsu PK, Wu YC. The feasibility of electromagnetic navigation-guided percutaneous microcoil localization for thoracoscopic resection of small pulmonary nodules. $J$ Thorac Cardiovasc Surg. 2019;157:e211-4. 